Carla Pires ${ }^{1}$

Marina Vigário ${ }^{2}$

Afonso Cavaco ${ }^{1}$
${ }^{1}$ Departamento de Sócio-

Farmácia, Faculdade de Farmácia, Universidade de Lisboa. Alameda da Universidade. 1649-004 Lisboa Portugal. cmbpires@gmail.com ${ }^{2}$ Departamento de Linguística Geral, Faculdade de Letras, Universidade de Lisboa.

\section{Brand names of Portuguese medication: understanding the importance of their linguistic structure and regulatory issues}

\author{
Nomes de marca dos medicamentos Portugueses: \\ sua estrutura linguística e aspetos regulatórios
}

Abstract Among other regulatory requirements, medicine brands should be composed of single names without abbreviations to prevent errors in prescription of medication. The purposes of the study were to investigate the compliance of a sample of Portuguese medicine brand names with Portuguese pharmaceutical regulations. This includes identifying their basic linguistic characteristics and comparing these features and their frequency of occurrence with benchmark values of the colloquial or informal language. A sample of 474 brand names was selected. Names were analyzed using manual (visual analyses) and computer methods (FreP - Frequency Patterns of Phonological Objects in Portuguese and MS word). A significant number of names (61.3\%) failed to comply with the Portuguese phonologic system (related to the sound of words) and/or the spelling system (related to the written form of words) contained more than one word, comprised a high proportion of infrequent syllable types or stress patterns and included abbreviations. The results suggest that some of the brand names of Portuguese medication should be reevaluated, and that regulation on this issue should be enforced and updated, taking into consideration specific linguistic and spelling codes. Key words Commercial medication brand names, Qualitative analysis, Language, Linguistics, Medication legislation
Resumo Entre outros requisitos regulatórios, o nome dos medicamentos de marca deve ser composto por um único nome e não integrar abreviaturas para evitar erros de medicação. Os objetivos do estudo foram: investigar a adequação de um grupo de nomes de medicamentos de marca portugueses à regulação farmacêutica do mesmo País; identificar as suas características linguísticas básicas e comparar essas características e a sua frequência com valores de referência da lingua corrente ou informal. Foi selecionada uma amostra de 474 nomes. Os nomes foram analisados com recurso a métodos manuais (análise visual) e automáticos (FreP - Frequency Patterns of Phonological Objects in Portuguese e o MS word). Um número significativo de nomes (61,3\%) não estava em conformidade com o sistema fonológico (relacionado com a forma sonora das palavras) e ortográfico do Português (relacionado com a forma de escrita das palavras), tinha mais de uma palavra, continha uma alta proporção padrões silábicos e acentuais raros, e incluía abreviaturas. Os resultados sugerem que alguns dos nomes das marcas medicamentos portugueses devem ser reavaliadas e os aspetos regulatórios atualizados, tendo em consideração as características específicas do sistema linguístico e ortográfico português.

Palavras-chave Denominação comercial do medicamento, Análise qualitativa, Linguagem, Linguística, Legislação de medicamentos 


\section{Introduction}

The names of medicinal products must be clear, legible and not associated with information of a promotional nature, thus ensuring their safe use and avoiding medication errors ${ }^{1,2}$. Preferably, these names should not contain ${ }^{2-4}$ :

- abbreviations, which might be ambiguous, unfamiliar, or unknown (and thus opaque) to the patients, pharmacists and/or prescribers,

- adjectives (e.g. 'rapid', 'hiper' in Portuguese or 'hyper' in English, etc.), which might suggest the existence of enhanced medicinal proprieties,

. symbols (e.g. '+'), which might also be ambiguous or misleading and, words with hyphens, because hyphens increase word extension and reflect morphologic or structural complexity ${ }^{5}$.

Considering the Portuguese regulation ${ }^{2}$ the names of medicines may be classified according to one of the three following groups: 1 ) names of fantasy, 2) the common designation of the drug followed by a brand, or 3) the common designation of the drug followed by the name of the applicant or the Marketing Authorization Holder. In particular, "the fantasy name corresponds to a term without a proper meaning, fruit of the imagination, devoid of correspondence in the reality, which objective is only to allow the production of sounds based on the reading of certain combinations of letters." In this context, the brand names of medicines correspond to the group 1 - names of fantasy, the names of branded generics medicines correspond to group 2 - the common designation of the drug followed by a brand; and the names of the generic medicines correspond to group 3 - the common designation of the drug followed by the name of the applicant or the Marketing Authorization Holder ${ }^{2}$. Also, in accordance with the Portuguese regulation (Law Decree 176/2006, article 3, available at: http://portalcodgdh.min-saude.pt/images/c/cf/ DL176-2006.pdf), "a medicine is any substance or associations of substances with preventive or curative proprieties on human diseases or on their symptoms through exerting a pharmacological, immunological or metabolic action to restoring, correcting or modifying physiological functions, or that might be used or administered in humans to establish a medical diagnostic."

In general, medicine brand names should be formed by just a single word ${ }^{2,4}$, thus making it easier to recall ${ }^{1}$. Despite the fact that there are reports cited in health written materials of patient deaths as a consequence of misunderstandings related to the interpretation of abbreviations ${ }^{6}$, according to some regulation their use might be acceptable in medicine brand names when they provide additional information on the characteristics of the medicinal product (e.g. route of administration $)^{2,7}$. The regulation on the formal characteristics of medicine brand names, such as those from the National Medicines Agency INFARMED, I.P. - Autoridade Nacional do Medicamento e Produtos de Saúde, I.P. (the Portuguese medicine authority of medicines and health products $)^{2}$, the European Medicines Agency ${ }^{7}$, or the Australian Medicines Agency ${ }^{8}$, does not include any specific recommendation on the adequate number or types of syllables, letters, or other characters (e.g. symbols). However, the Food and Drug Administration (FDA) (the United States Department of Health and Human Services agency that among other is also responsible for assuring the safety and efficacy of the medicines) is somewhat more specific in this respect: (a) the applicant or sponsors are encouraged to provide a written transcription of the intended pronunciation of the brand (e.g. using the phonetic alphabet, that is an alphabet internationally accepted to transcribe all sounds/languages in non-ambiguous way, which might be consulted in the following link https://www.langsci.ucl. ac.uk/ipa/IPA_chart_(C)2005.pdf), because this might impact on how the names are pronounced in practice, to promote their precise identification and the prevention of medication errors, and (b) modifiers (e.g. abbreviations) need to be explained/detailed, because their use might suggest different meanings to health professionals or patients. Furthermore, the FDA critically reviews all proposed names, for instance using databases and computational linguistic methods to evaluate similar spellings, and orthographic or phonological similarities, that are similarities related to the written or sound form of the words, respectively. In these evaluations, attributes are screened such as: identical prefix (the use of an affix at the beginning of a word), infix (the use of an affix inside the word), suffix (the use of an affix at the end of a word), length, stress, and number of syllables". The affix might be considered a segment (or a specific part of a word) that act as a modifier ${ }^{5,9}$.

The length of brand names, for instance, is a fundamental issue for their development and conception. In general, short names are more easily spelled, pronounced and recalled (e.g. names with 4 or less letters in the case of English words, as tall, ball call, etc.). Nevertheless, overly short names are also not advisable, because 
these words are more likely to present common sounds or similar orthographic parts (e.g. phonological neighbors, which are words containing at least one common sound/part, such as Actos ${ }^{\circledR}$ and Actonel ${ }^{\circledR 4,10-13}$. According to Lambert et al. ${ }^{14}$, 32,748 names of branded medicines from a database of medicines marketed in the United States, contained an average of 1.7 words, 3.5 syllables, and 10.3 letters $(S D=6.74)$. Another source reports that the most common US brand names comprised 8 letters ${ }^{12}$. Word size in number of letters has been shown to impact on subjects' word recognition. This has been shown for instance in the English Lexicon Project (ELP). ELP is a multicenter study that among other aims to collect a large number of data on behavioral tasks with words and non-words and that enrolls presently six testing Universities (http://elexicon.wustl. edu/). In this project, 33,006 words (with 3 to 13 letters) were evaluated and 816 participants were enrolled in a lexical decision task, that is an experimental task in which the participants had to recognize different words ${ }^{15,16}$. Results from this study support that, irrespective of the lexical frequency (the probability of using a word in a certain language), the number of syllables, and the number of neighbors (different names that are almost identical in terms of their sound form), the accuracy and reaction time in the recognition of words correlate with the number of letters of the word. In particular, an inhibitor effect in word recognition was detected on words with 8 to 13 letters, with these words taking longer to be recognized than shorter ones ${ }^{15}$. In another study (140 participants), specifically conducted on Portuguese, three disyllabic words (words with two syllables), as tema in Portuguese (syllabic division: te.ma) or 'theme' in English, and three trisyllabic words (words with three syllables), as tomada in Portuguese (syllabic division: to.ma. da) or 'capture' in English, were tested, in an auditory and oral task (first the words were orally produced and then the participants had to orally reproduce all their segments or sounds). It was found that longer words were more prone to be orally produced with errors: $46 \%$ of the disyllabic words were orally produced correctly vs. $30 \%$ of the trisyllabic words ${ }^{17}$.

Discrepancies between the general sound patterns of the language and the sound patterns found in medicine brand names may also increase readability problems. There are a number of properties that characterize words in European Portuguese. In what follows we describe some basic features of the language that will allow us determining the extent to which medicine brand names may deviate from the common sound patterns found in European Portuguese words.

In European Portuguese, word stress may occur in one of the three final syllables in a word ${ }^{18,19}$. Depending on stress location, words are classified as: (a) oxitone (stress on the last syllable), (b) paroxitone (stress on the penultimate syllable) and, (c) proparoxytone (stress on the antepenultimate syllable $)^{19-21}$. Portuguese words with penultimate and final stress are more frequent than words with antepenultimate stress ( $74 \%$ and $22.8 \%$ vs $3.2 \%$, respectively $)^{20}$. Importantly, word stress is a fundamental issue to the appropriate processing, understanding, and intelligibility of speech, as has been shown in several studies on stress patterns $\mathrm{s}^{22,23}$. For example, in a recognition task of spoken English words, it was found that both native (English-speakers) and non-native English speakers (Dutch speakers) used stress patterns to identify the relevant words $\mathrm{s}^{22}$.

Other basic linguistic features that influence how words are processed, read, or written, include: (a) the phonetic segments, or the elementary sounds of the language, that compose words, such as consonants $(\mathrm{C})$, vowels $(\mathrm{V})$, nasals $(\mathrm{N})$ (vowel and vowel-like sounds that are produced with nasal resonance) and glides $(\mathrm{G})$ (vowel-like sounds that must occur with a vowel that functions as a syllable nucleus) and (b) the patterns of combinations of sounds within the syllables the patterns of combinations of sounds within the syllables that compose words - e.g. the Portuguese word medicamento in Portuguese or 'medicine' in English is formed of 5 syllables (syllabic division: me.di.ca.men.to), but only 2 syllable types, 4 of the type CV (me,di, ca and to) and 1 of the type CVN $(m e n)^{5,24,25}$.

The frequency of segments and syllable types may influence word processing. For instance, in studies involving word naming and lexical decision tasks, it has been found that words including more frequent syllable types were recognized faster than words with less frequent types of syllables ${ }^{24,25}$. In European Portuguese, like in other languages, segments (for the most of the categories $\mathrm{C}$ and $\mathrm{V}$ ) are grouped into syllables depending on their sound properties. Some rare consonantal sequences constitute ill-formed consonant clusters, and they trigger the insertion of a vocalic position (a V-Slot). This vocalic position allows segments to be parsed into syllables that conform to the language general laws for syllable formation. For example, while a consonant cluster like tr yields a well-formed syllable in Por- 
tuguese (as in the word dentro in Portuguese or 'inside' in English, which is syllabified as den.tro), a consonant cluster like $f t$ in the Portuguese word afta or 'aphthous stomatitis' in English yields a ill-formed syllable structure (because in the Portuguese sound system $f t$ cannot start a syllable, as in $a$.fta, and $f$ cannot close a syllable either, as in $a f . t a$ ). In the latter type of cases, a vocalic position emerges between the two consonants (a V-slot). V-slots allow the syllabification of words containing problematic consonant sequences, as in a.fV.ta, which then exhibits the typical syllabic pattern of the language (the pattern where syllables are formed of one consonant and one vowel, which is the most frequent syllable type in Portuguese $)^{19}$. As a result, the word afta may be realized as afeta (or, to be more precise, ['afite] using the international phonetic alphabet).

The frequency of V-slot in available corpora of European Portuguese (or databases of texts of common language), such as the TQT (comprises 22994 words) and TA90PE1 ${ }^{1}$ (comprises 64757 words), is very low, corresponding to $0.07 \%$ and $0.2 \%$, respectively. Both the corpus TA90PE and $\mathrm{TQP}$ are formed by common words, since the first is the result of the transcription of colloquial interviews from the different regions of Portugal, and the second is formed by transcriptions of oral samples collected in the Terra Quente Transmontana (a region in the North of Portugal) ${ }^{18,26}$. What is important for us here is that the presence of a $\mathrm{V}$-slot in a word indicates that a given consonantal string is rare and phonologically problematic ${ }^{18,26}$.

Rare syllable types in European Portuguese include VG or CVGC. For instance, in the corpora just cited, these syllable types have been reported to account for only $1.51 \%$ and $1.21 \%$ of the total number of occurring syllables, respectively.

Importantly, above $90 \%$ of syllables found in Portuguese corpora belong to a very small subset of syllable types, composed of only 10 syllables types (including CV, CVC, CCV) ${ }^{27}$.

Using a large sample of Portuguese medicine brand names, the purposes of this study were:

1. to investigate the compliance/agreement of medicine brand names with Portuguese regulation,

2. to characterize some of their basic linguistic and orthographic features,

3. to compare their basic linguistic features with reference frequency values of common language, thus assessing the extent to which the form of medicine brand names may deviate from the most common sound patterns found in European Portuguese.

\section{Method}

A random sample of Portuguese medicine brand names was obtained from the Portuguese prescribing guide ${ }^{28}$. Approximately $25 \%$ of all medicine brand names available in this guide (531 brand names) were randomized, of which 57 were excluded for either being repeated (to avoid redundant analysis), or for comprising international nonproprietary names or the generic names used worldwide (to assure that only brand names were included in this study). The main reasons for not selecting generic names were the following: (a) generic and brand names present different structures, because generic names are formed by international nonproprietary names in association with the name of the marketing authorization holder and brand names are formed by invented names ${ }^{2}$, and (b) linguistic and orthographic rules are already available to adapt to Portuguese the names of generic medicines that are internationally marketed ${ }^{29,30}$. For instance, for the translation of the name of active substances (e.g. generic names) the American Association of Physicians recommends: the use of $i$, $t, f$ and $e$ instead of $y, t h, p h$ and $a e$ respectively, and to avoid $k$ and $w^{29}$. These rules are very similar to those of the World Health Organization ${ }^{30,31}$, and they are respected in the translation of Portuguese generic names which follow these general rules (e.g. the $i$ is used instead of $y$, in the case of 'hydrocortisone' in English vs. hidrocortisona in Portuguese $)^{30}$. Consequently, it was considered that the name of generic medicines should be studied in an autonomous investigation.

The assessments of the legal requirements were based on the criteria set out in the pharmaceutical regulation(e.g. names should comprise only one word and preferably not contain abbreviations $)^{2,7,8}$.

The medicine brand names were manually classified into 4 groups: Group 1 comprised names that might be considered as not being written in accordance with the orthographic system of European Portuguese ${ }^{32}$, Group 2 comprised names not written in accordance with that system, while Group 3 and 4 comprised names written in accordance with that system. This classification was performed taking into account the new Portuguese orthographic rules, given the inclusion of the letters $k, y$ and $w$, as belonging to the Portuguese alphabet. However, it is important to highlight that these new rules only started to be mandatory for Brazil in 2009 and in Portugal they will only become mandato- 
ry in 2016 (www.portaldalinguaportuguesa.org/ acordo.php). These three letters $(k, y$ and $w)$ were introduced in the Portuguese alphabet essentially because of the large scale introduction in the language of proper names and loan words from English origin (as currently happens in other languages of the world as well). In general, the use of these words only represented a very limited part of the Portuguese corpora. For instance, this can be seen searching the corpus CETEMPublico (a database with190 millions of words and specifically formed by journalistic texts, freely available at www.linguateca.pt/ACDC, where words like 'Hollywood' or 'Gulbenkian' clearly display a deviant orthographic shape). Given this, Group 1 includes names containing letters that were not part of Portuguese alphabet until recently $(k, y, w)$. Group 2 includes names containing combinations of letters not allowed in the European Portuguese orthographic system (e.g. strings with double letters such as $t t$ or $z z$, or ending with consonants different from $r, l, s$, $m, n$ or $x$, such as $t$ or $d$, and so forth). Group 3 includes names written in accordance with the European Portuguese orthographic system and excluding the names that comprise the letters $k$, $y$ and $w$ (in accordance to the rules of the previous orthographic convention legally approved) and Group 4 includes names integrating rare segments, such as names ending in $n$ or $x$, or names containing $\mathrm{V}$-slots (names containing unusual sequences of consonants such as $f t)^{27}$.

It was pre-defined that if a name were to cumulatively comprise the letters $k, y$ and $w$ (Group $1)$, combinations of non-canonical segments or combinations of letters non-existent in Portuguese (Group 2) and/or end in $n$ or $x$ or contain V-slots (Group 4), this name would be assigned as an element of Group 1, and that if a name were to cumulatively comprise combinations of non-canonical segments (Group 2) and/or end in $n$ or $x$, or contain V-slots (Group 4), this name would be assigned as an element of Group 2. In both situations the names were classified in accordance to the situation that was considered as more deviant from the natural Portuguese patterns.

The variables studied are described in Chart 1 , where the frequency of the type of syllables was also quantified. For our purposes, syllable types were classified as frequent or rare. The 10 more frequent syllabic of the Portuguese European referred to in the introduction section are the following CV, V, CVC, CVGN, CVN, VC, CVG, VN, $\mathrm{CCV}$ and $\mathrm{VG}^{26,27}$. For the purpose of the present study, syllable types were classified as frequent if they belong to the set of the ten most frequent syllable types in European Portuguese, or rare is they are not part of that $\operatorname{set}^{27}$.

The linguistic variables 1 and 3 to 6 were quantified using the informatics tool FreP - Frequency Patterns of Phonological Objects in Portuguese $^{33}$. Given the algorithm used in this tool (a) the individual stress patterns of all the words that constituted the brand names were classified in accordance with the natural pronunciation patterns of Portuguese, therefore the possible existence of alternative non-Portuguese stress was not investigated - the rational here is that, by default, Portuguese users will pronounce medicine brand names following the general rules of the language for stress placement; (b) the letters $y$, $k$ and $w$ were respectively processed as $i, c$ and $v$; and (c) the doubling of letters that does not exist in Portuguese was processed as just one letter, for instance $t t$ was processed as $t$, because this corresponds to the way these letter sequences are pronounced by default. This way, none of the non-canonical names (foreign names not adapted to Portuguese) were analyzed in accordance to the phonologic and orthographic rules of others language. The options (a), (b), and (c) reflect the average European Portuguese reader, given that $41 \%$ of the Portuguese population self-report not to speak any other language ${ }^{34}$ : the Portuguese population is assumed to follow the natural phonological patterns of their native language when reading medicine brand names.

We should notice that European and Brazilian Portuguese present different phonologies. Thus, words may be read with different pronunciations and reference values for the frequency of occurrence of segments, syllables and stress patterns may also vary. Therefore, the results we report here cannot generalize to other varieties of Portuguese. We believe a specific evaluation of medicine brand names used in Brazil similar to the one developed here would be recommended.

MS Word 2010 for Windows 7 was used to quantify the number of: (a) letters (variable 2), (b) words with a hyphen (variable 7), and (c) expressions or words not allowed according to regulatory requirements (variable 9), applying the automatic search function of this program. Names containing abbreviations, numbers, or symbols (variable 8) were manually identified. Abbreviations may be classified as acronyms (or abbreviations susceptible of being read as a single word, e.g. PA, which English full correspondence is 'pressure aerosol' - see http://www.oxforddictionaries.com/ 
Chart 1. Variables studied.

\begin{tabular}{|c|c|c|c|}
\hline Number of & Method & $\operatorname{Objective}(s)^{a}$ & Citation(s) \\
\hline 1 - Orthographic words (Tokens) & FreP & $1,2,3$ & $\begin{array}{l}\text { (Handler et al., 2004; Infarmed, 2012; } \\
\text { Institute for safe medication practice, } \\
2011)^{1,2,4}\end{array}$ \\
\hline 2 - Letters & MS Word & 2,3 & $(\text { Lambert et al., 2005) })^{12}$ \\
\hline 3 - Syllables & FreP & 2,3 & $\begin{array}{l}\text { (Food and Drug Administration, 2010; } \\
\text { Vigário, Martins, \& Frota, 2006) } \\
\text { 9,26 }\end{array}$ \\
\hline 4 - Syllable types & FreP & 2,3 & (Vigário, Martins, \& Frota, 2006) ${ }^{26}$ \\
\hline $\begin{array}{l}5 \text { - Consonants, vowels, glides, } \\
\text { and V-slots }\end{array}$ & FreP & 2,3 & $\begin{array}{l}\text { (Lambert et al., 2005; Mateus \& Andrade, } \\
\text { 2000; Vigário, Freitas, \& Frota, 2006) } \text { (12,19,27 }^{2}\end{array}$ \\
\hline 6 - Words per stress position & FreP & 2,3 & $\begin{array}{l}\text { (Aguiar \& Vigário, 2010; Food and } \\
\text { Drug Administration, 2010; Mateus \& } \\
\text { Andrade, 2000)9,18,19 }\end{array}$ \\
\hline 7 - Hyphenated words & MS Word & $1,2,3$ & (Hyönä et al., 2004; Villalva, 2000) \\
\hline $\begin{array}{l}8 \text { - Words containing abbreviations } \\
\text { (acronyms or initialims), numbers } \\
\text { or symbols }\end{array}$ & Manual & $1,2,3$ & (Mateus et al., 2004) $)^{32}$ \\
\hline $\begin{array}{l}9 \text { - Expressions or words } \\
\text { not allowed according to the } \\
\text { regulatory requirements }\end{array}$ & MS Word & 1 & $(\text { Infarmed, 2012) })^{2}$ \\
\hline
\end{tabular}

${ }^{a}$ Objectives: 1. to investigate the compliance of medicine brand names with regulations; 2 . to characterize their basic linguistic features, and 3. to compare the values of their basic linguistic features with reference values for the language. ' ${ }^{\text {e.g. ' }}$ 'rapid', 'hiper'.

definition/english/acronym) or initialism (or an abbreviation susceptible of being read by pronouncing the initial letters, e.g. FML, which English full correspondence 'fluorometholone' - see http://www.oxforddictionaries.com/definition/ english/initialism $)^{35}$. Thus, a qualitative analysis to distinguish between acronyms and initialisms was performed (Chart 1). This classification was done in the following way, one of the researchers read all abbreviations (acronyms or initialisms) and immediately after classified the abbreviation as an acronym or as an initialism. One expert in linguistics re-checked all the linguistic data, using the same procedure.

The occurrence of abbreviations in the names of prescription medicines and over-the-counter medicines (OTC) was specifically quantified and analyzed. This quantification was considered pertinent, because OTC might be acquired without the direct intervention of a health pro- fessional ${ }^{36,37}$, and this may increase the potential for problems originated from the presence of abbreviations in medicine brand names.

Despite the recommendation to not use abbreviations in medicinal information, such as package leaflets, when they are used their full meaning should correspond to the official language of the country where the medicine is marketed (e.g. CR or 'Controlled-Release' for English $)^{38}$. In addition, according to some regulation the use of abbreviations in medicine brand names might be acceptable if they add information about the medicine (for instance, the abbreviation $S$ in the case of the medicine Kompensan $S^{\circledR}$, might be considered useful for patients and health professionals, as a way of noticing the presence of a particular substance; Simethicone, in this medicine) $)^{2,7}$. For this reason, the following aspects were checked by a pharmacist: (a) presence/absence of the full meaning of abbreviations 
in the content of the package leaflet, and (b) presence/absence of abbreviations corresponding to a language other than Portuguese.

The full meaning of abbreviations was confirmed in the package leaflet, when present. In the cases where the full meaning of an abbreviation was not described in the package leaflet, the information was obtained in the official sites for medical abbreviations such as Medilexicon ${ }^{39}$ for English abbreviations, or in the glossary of the National Prescribing Guide for Portuguese abbreviations ${ }^{28}$. It was important to verify the full correspondence of English abbreviations because, contrary to what would be expectable, abbreviations with full correspondence in English were also found within the brand names of Portuguese medicines. The package leaflets were consulted using a public Portuguese data base: the Infomed (available at https://www.infarmed.pt/infomed/ inicio.php $)^{40}$.The full meaning of abbreviations was not checked on the outer package of the respective medicines, because of economic and logistic constraints that restricted access to such a large number of packages.

\section{Results}

\section{Distribution by the 4 classificatory groups}

Overall, $24.3 \%$ of the names (115 of 474 names) were not written in accordance with the Portuguese orthographic system (Group 2). These names comprised non-canonical segments (or combinations of letters non-existent in Portuguese), such as the segments $t t$ or $l l$, or the names ending in $t, d$ or $c$ (e.g. Nicotinell ${ }^{\circledR}$, Novynette ${ }^{\circledR}$, Atrovent ${ }^{\circledR}$, Ronic ${ }^{\circledR}$ and Sinecod $\left.{ }^{\circledR}\right)$. Also, 10.8\% included the letter(s) $k, y$ or $w$ (e.g. Daktacort ${ }^{\circledR}$, Alorexy ${ }^{\circledR}$, and Twinrix ${ }^{\circledR}$ ) (51 of 474 names) (Group 1). Data are presented in Figure 1.

Names ending with $t, d$, and $c$ were the most common in Group 2 (37.4\%; 43 cases out of 115 names). Names ending in $n$ were the most prevalent in Group 4 (63.7\%; 79 cases out of 125 names). This group comprises names with rare structures in Portuguese, such as, the names ending in $n$ (e.g. Rocephin $\left.{ }^{\circledR}\right)$ or $x$ (e.g. Dostinex $\left.{ }^{\circledR}\right)$.

In the group of names comprising the letters $k, y$ and $w$ (Group 1), 8 names ended in $n$, 7 names contained more one letter of the type $k, y$ or $w$, and 5 comprised $\mathrm{V}$-slots. In the group of names containing non-canonical segments (or combination of letters that do not exist in Portuguese) (Group 2), 9 names ended in $n$, and 9 names comprised $\mathrm{V}$-slots. The names were different in every case.

Among the 474 names: 384 (81\%) were formed by one orthographic word, 64 (13.5\%) by two words, and $89(18.7 \%)$ by more than two words. A few names with 4,6 , and 9 orthographic words were also identified. Overall the 474 names comprised 615 words. The distribution of the number of words per name is presented in Figure 2.

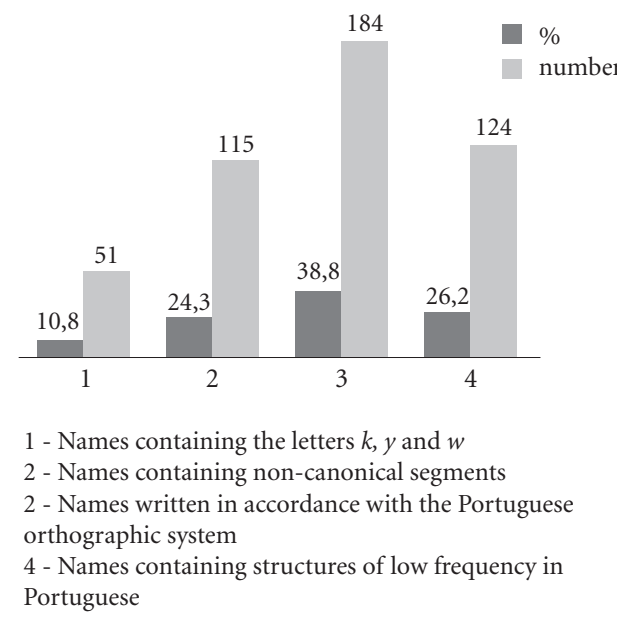

Figure 1. Percentage and names distributed by groups.

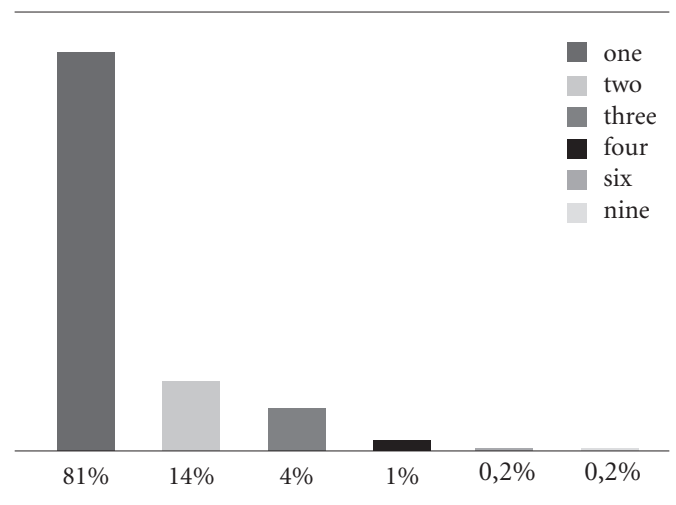

Figure 2. Percentage of the number of words in medicine brand names. 


\section{Word length: number of orthographic words, letters and syllables}

The brand names contained 2 to 25 letters, of which $70.6 \%$ had 6 to 9 letters. Median of 8 and a mean of $8.7(\mathrm{SD}=3.2)$ letters per name.

The average number of syllables per brand name was $3.7(\mathrm{SD}=1.5)$. Among the 615 orthographic words that formed the 474 names, $96.1 \%$ contained 4 or less syllables, $11.4 \%$ a single syllable, $3.9 \%$ contained between 5 and 7 syllables and none contained more than 8 syllables.

\section{Syllable types, segments, and V-slots}

The ten most frequent syllable types in European Portuguese explain the syllabic structure of almost all brand names (93.2\%; 1,649 of the 1,769 syllable occurrences). 116 names (24.5\%) comprised at least one rare syllable type. Overall, 120 rare syllable types were identified: 13 $(10.8 \%)$ in the names of Group 1, $28(23.3 \%)$ in the names of Group 2, $29(24.2 \%)$ in the names of Group 3, and $50(41.7 \%)$ in the names of Group 4.

The 474 names were formed by 4,066 segments (with an average of 9 segments per word; $\mathrm{SD}=3$ ). The number of segments was determined by the sum of the number of consonants, vowels, and glides. The percentage of V-slots $(\mathrm{n}=$ $39,2.2 \%)$ was calculated in relation to the total number of syllables $(\mathrm{n}=1,769)$, as a way of constituting an indicator of their occurrence. Data are presented in Table 1.

\section{Number of words per stress position}

The sum of words with final (385), penultimate (155) and antepenultimate stress (5) was 545. In general, final stress was predominant ( $70.6 \%$ of 545$)$, when compared to penultimate (28.4\% of 545$)$, and antepenultimate $(0.9 \%$ of 545) stress.

\section{Hyphenated words}

Hyphens were identified in $4.2 \%$ of names. A name with 2 hyphens was also found (Ben-u$\left.\operatorname{ron}^{\circledR}\right)$.
Table 1. Distribution of syllable types, segments, and $\mathrm{V}$-slots in medicine brand names.

\begin{tabular}{|c|c|c|}
\hline & $\begin{array}{l}\text { Number of } \\
\text { occurrences }\end{array}$ & $\%$ \\
\hline $\begin{array}{l}\text { Total number of syllables } \\
\text { (more frequent }+ \text { rare) }\end{array}$ & 1769 & 100 \\
\hline \multicolumn{3}{|c|}{ Ten most frequent syllabics types } \\
\hline $\mathrm{CV}$ & 863 & 48.8 \\
\hline $\mathrm{V}$ & 147 & 8.3 \\
\hline $\mathrm{CVC}$ & 393 & 22.2 \\
\hline CVGN & 5 & 0.3 \\
\hline $\mathrm{CVN}$ & 58 & 3.3 \\
\hline VC & 36 & 2 \\
\hline CVG & 8 & 0.5 \\
\hline $\mathrm{VN}$ & 27 & 1.5 \\
\hline $\mathrm{CCV}$ & 108 & 6.1 \\
\hline VG & 4 & 0.2 \\
\hline Total (more frequent) & 1649 & 93.2 \\
\hline \multicolumn{3}{|l|}{ Rare syllable types } \\
\hline VGC & 1 & 0.1 \\
\hline CCVC & 34 & 1.9 \\
\hline CCVCC & 9 & 0.5 \\
\hline CCVG & 1 & 0.1 \\
\hline CCVN & 13 & 0.7 \\
\hline CGVC & 2 & 0.1 \\
\hline CGVN & 1 & 0.1 \\
\hline CVCC & 52 & 2.9 \\
\hline CVGC & 2 & 0.1 \\
\hline VCC & 1 & 0.1 \\
\hline Other rare & 4 & 0.2 \\
\hline Total (rare) & 120 & 6.8 \\
\hline \multicolumn{3}{|l|}{ Segments ${ }^{\mathrm{a}}$ and $V$-slots } \\
\hline Consonants & 2313 & 56.9 \\
\hline Vowels & 1730 & 42.5 \\
\hline Glides & 23 & 0.6 \\
\hline Total & 4066 & 100 \\
\hline Segments average & 9 & \\
\hline Standard Deviation & 3 & \\
\hline V-Slot ${ }^{\mathrm{b}}$ & 39 & 2.2 \\
\hline
\end{tabular}

C: consoants; V: vogals; G: glides; N: nasal. ${ }^{\mathrm{a}}$ Segments = consonants + vowels + glides. ${ }^{\mathrm{b}} \mathrm{V}$-slots percentages were calculated in relation to the total number of syllables $(\mathrm{n}=1769)$.

\section{Names containing abbreviations, numbers and symbols, and abbreviations full meaning}

Thirty-six brand names (7.6\% of 474$)$ contained abbreviations and in one case two abbreviations were found in a single name, hence 37 abbreviations were identified: 4 belong to OTC names, 3 might be read as acronyms, with the remaining being read as initialisms, and 8 present full correspondence in English instead of Portu- 
guese. In only 3 cases was the full meaning of the abbreviations described in the package leaflets.

With respect to the presence of numbers and symbols, 6 brand names contained numbers in their structure (1.3\% of 474 names) and 1 brand name enclosed a symbol, namely ' + ' (see Chart 2).

\section{Prohibited expressions}

Eight prohibited expressions ${ }^{2}$ were detected in 21 brand names (Chart 2).

\section{Discussion}

\section{Letters only recently introduced to the Portuguese alphabet and non-canonical segments}

In the present study, the occurrence of names with letters $k, y$ and $w$ or containing non-canonical segments (associations of letters that are non-existent in Portuguese, such as $t t$ ), was quite prevalent, affecting almost half of the names. Given that it is well documented that the mental processing of words is dependent on an orthographic and phonological code (respectively related

Chart 2. Abbreviations, names and expressions not recommended/allowed.

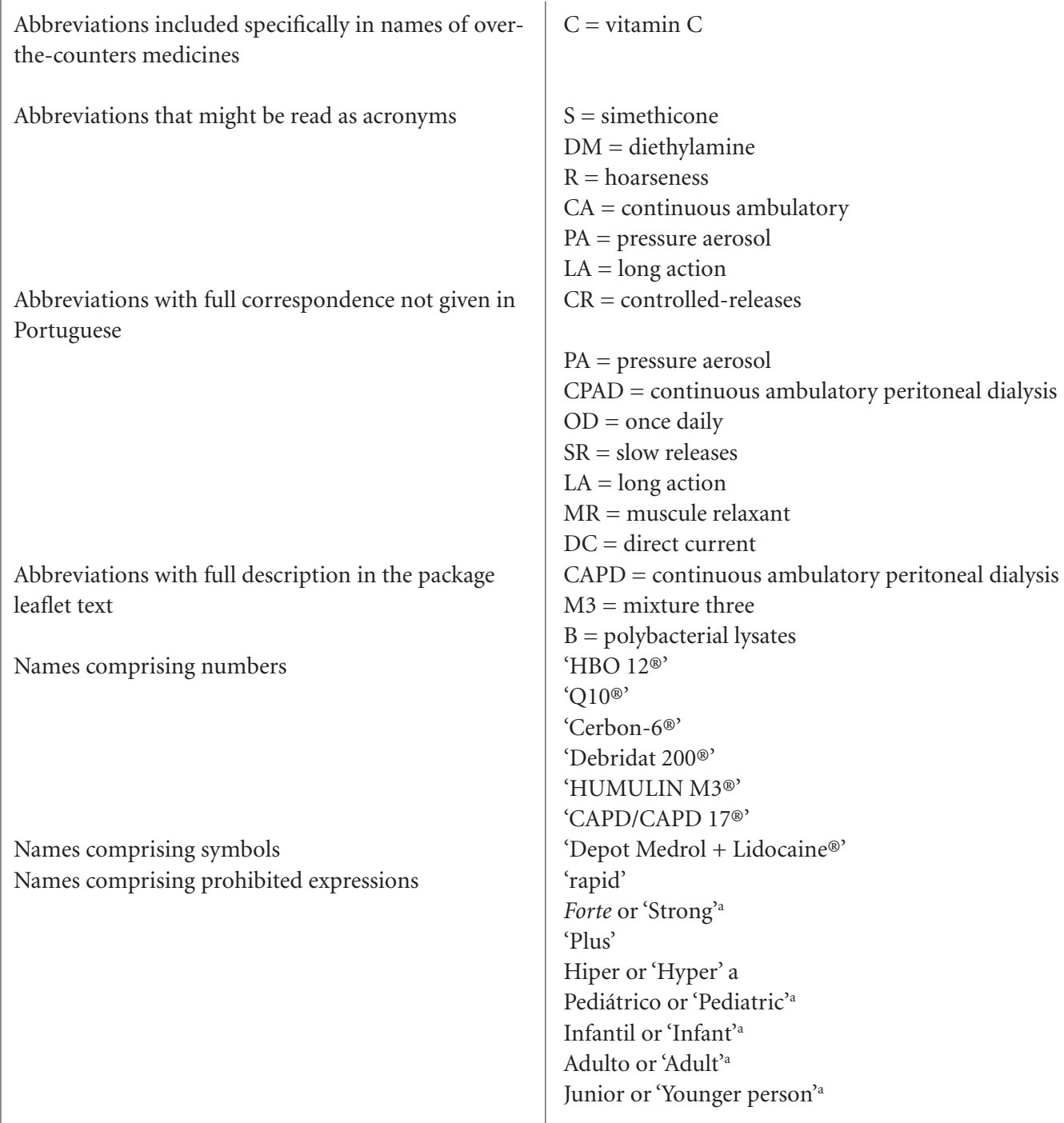

a The Portuguese word in italic and the correspondent translation between quotation marks. 
with the written or oral forms of the words $)^{41,42}$, this type of letters and segments might have a negative impact on the adequate memorization, recall and pronounceability of words, and consequently not be suitable to form brand names for medicines to be used by the Portuguese speaking population. In Portuguese, orthography presents a close correspondence to the sound, i.e. each letter corresponds to one sound. The specific cases of names containing double letters, usually consonants (e.g. $t t$ or $z z$ ), seems to increase reading complexity: not only these cases deviate from the orthographic rules of the language, but they are formed of more letters than those required, since two characters represent single sound. Overall, the fact that these orthographic patterns were different from those that the readers are familiar with might cause doubts as to the way words are correctly read, written or pronounced. In this context, brand names that cumulatively include linguistic features from different groups (e.g. names containing letters recently introduced in the Portuguese alphabet, such as the $k, y$ and $w$ plus non-canonical segments) are likely to be more complex and processed more poorly.

\section{Number of orthographic words}

A considerable number of names included at least two orthographic words. This might negatively influence their adequate pronunciation and memorization ${ }^{1,2,4,8,12,14,43}$.

\section{Word length: \\ number of letters and syllables}

Most of the names in this study contained up to three syllables, a pattern of distribution also found in the common/colloquial Portuguese, such as that represented in the TQP and TA90PE (see the introduction $)^{26,27}$. Thus, the word length patterns of the brand names also were very similar to those of others names available on European Portuguese databases corpora ${ }^{26,27}$.

Although the average length of Portuguese brand names seems appropriate, as far we known there are no studies specifically on the appropriate length of Portuguese brand names. Therefore, it would be desirable to confirm the suitability of the brand names length before their marketing approval (e.g. through using experimental studies). A number of facts suggest, nevertheless, that the average length of the Portuguese brand names may be appropriate: 1) the brand names slightly longer than the average Portuguese words (or the names with 3 or 4 syllables) ${ }^{26,27}$, are possibly more appropriate to feature on the outer packaging and to use within the text of the package leaflets, because presumably these names will be better distinguished and less confusable, 2) overly long names (namely names with more than 4 syllables) are not advisable so as to assure their adequate memorization, recall and pronunciation $^{10-12}$, because longer words take more time to be identified (e.g. in reading tasks) ${ }^{44}$, and 3) too short names (or the names with less than 3 syllables) are also not advisable, because they are usually related with a greater number of phonological neighbors (different names that are almost identical in terms of their sound form $)^{45}$. This situation probably increases the possibility of correspondences with other words and therefore the risk of confusion between similar names of medicines.

The Portuguese medicine brand names exhibit an average size in terms of number of letters and syllables very similar to those described in studies involving names of medicines marketed in other countries ${ }^{14}$. This was not surprising given that many of these medicines were also available in other countries with the exact same name, consequently confirming that it is very likely that these names were not initially invented/developed in Portuguese speaking countries ${ }^{46}$.

\section{Syllable types, segments, and V-slots}

The predominance of the ten most frequent syllable types in European Portuguese ${ }^{27}$ apparently confirms the existence of some similarity between the structure of brand names and the general Portuguese words. Nevertheless, it was possible to identify in the brand names a high proportion of syllable types that are rare in Portuguese (e.g. CVCC and CCVC) ${ }^{27}$. As expected the rare syllable types were much more prevalent (almost twice as many) in the group of names containing structures of low frequency, such as the names ending in $n$ or $x$, because these deviant structures will indirectly promote the formation of rare syllable types. Again, deviant syllable structure might yield lower readability of some Portuguese medicine brand names.

A high prevalence of vowels and consonants was found in the sample of names, similar to those in other European Portuguese corpora (or databases of texts that are used to estimate the frequency of words, segments, letters, symbols, or punctuations signs in a certain language $)^{18,26}$. By contrast, a lower proportion of glides and a great- 
er proportion of $\mathrm{V}$-slots were found in relation to the common patterns. For instance, the segments were distributed as follows: $48 \%$ vowels, $46 \%$ consonants, $5.8 \%$ glides, and $0.2 \%$ V-slots in the corpus TAP90PE $(22,994$ words) (we recall that these are rare elements that emerge to break sequences of segments that do not form proper syllables in the language, as $d v$ in the Portuguese word advogado or 'lawyer' in English) ${ }^{18}$. Assuming that V-slots, only emerge with segmental sequences that are not allowed by the general laws of the language for the combination of segments, the proportion of $\mathrm{V}$-slots found in brand names also suggests the low readability of some Portuguese brand names.

\section{Stress distribution}

The frequency of the three stress patterns in the medicine brand names under observation was clearly different from that commonly found in the language ${ }^{18,26}$. In fact, in our data words with final stress were more prevalent than words with penultimate stress. As we have seen in the introduction section, according the data available in a reference database of Portuguese, words with penultimate stress are more frequent than words with final stress $(22.8 \%)$ and antepenultimate stress $(3.2 \%)$, and similar results have been reported elsewhere $\mathrm{e}^{18,20,26}$.

Despite the proportion of the three stress patterns being clearly different from those in common language, it is not expected that this should produce a very significant negative impact on the readability of names, because the words with stress on the last syllable are also fairly common in Portuguese.

\section{Names containing hyphenated words}

The proportion of words with a hyphen was very limited in the sample of brand names. This seems to be a good result, given that the presence of hyphens increases word extension and correlates with a higher morphological complexity, since they indicate that the names are formed by associations of two or more words (as in arco-íris in Portuguese or 'rainbow' in English). Therefore the use of hyphenated word in medicine brand names probably also negatively impacts on their readability ${ }^{3,5}$.

\section{Names containing abbreviations}

Various abbreviations were identified in the sample of brand names, although their use is not recommended ${ }^{1,2,4,12}$. Additionally, many of these abbreviations referred to English technical terms (e.g. CR meaning 'controlled-release' or PA meaning 'pressure aerosol'), which might represent an additional issue to Portuguese monolingual speakers, and also to non-health professionals who are usually not familiarized with the use of technical terms. Unexpectedly, in many cases the full meaning of each abbreviation was also not detailed in the text of package leaflets. Therefore names containing abbreviations might be considered less readable and in some cases compromise the safe use of medicines ${ }^{6,47}$.

In the case of OTC medicines, exceptionally some abbreviations used in their names might be considered compliant with the legal requirements, as a result of their potential advantageous $^{2}$. For instance: (a) in the case of Aspirin $\mathrm{C}^{\circledR}$ and Kompensan $\mathrm{S}^{\circledR}$, the $\mathrm{C}$ and $\mathrm{S}$ probably promote a better differentiation relative to other medicinal products with similar names (Aspirin $^{\circledR}$ and Kompensan ${ }^{\circledR}$, respectively) or allow the composition of the medicine to be better identified, (b) in the case of Mentocaina- $\mathrm{R}^{\circledR}$, the $\mathrm{R}$ (rouquidão in Portuguese or 'hoarseness' in English) constitutes a cue to identify one of the symptoms that the medicine treats, and (c) in the case of DM, the DM (dores musculares in Portuguese or 'muscle pain' in English) might also be associated with the treatment of a specific health issue. However, if the patients do not have any previous knowledge about the medicine, the use of these abbreviations is not likely to be beneficial, because they will not be able to assign any meaning to these abbreviations.

The fact that almost all abbreviations identified in this study were acronyms, presents even more readability problems, because the pronunciation of initialisms is easier than that of acronyms ${ }^{34}$.

\section{Names containing numbers and symbols}

Some names were identified comprising numbers or symbols in this study. Although their use is not recommended because of the risk of patients' misinterpretation and low readabili$\mathrm{ty}^{2}$, it is possible to identify some possible positive reasons for their use: (a) it may facilitate patients' memorization and recall of medicine brand names by increasing their phonological 
extension - in other words, the oral form of the name is longer than the correspondent oral form in the case of the symbol being omitted (e.g. Cerbon- $6{ }^{\circledR}$ is read as Cerbon-seis in Portuguese or 'Cerbon-six' in English; ' + ' is read as mais in Portuguese or 'more' or 'plus' in English); or (b) it may promote the distinction between similar brand names (e.g. the use of M3 probably helps to better distinguish between different types of Humulin ${ }^{\circledR}$ insulins). By contrast, their use might also be associated with negative reasons such as increasing the complexity of medicinal brand names, as well as constituting an element of promotional nature (e.g. if their use increases the memorization of medicine brand names in particular by healthcare prescribers). Overall the use of numbers and symbols in medicine brand names for possible reasons of a promotional nature should be adequately controlled and supervised by marketing authorization holders and health authorities.

\section{Names containing prohibited expressions}

Also some names containing legally unacceptable expressions were identified, such as Hiper in Portuguese (or 'Hyper' in English), 'Strong' and 'Plus', also contributing to the possible existence of non-adequate names. The use of these expressions might (a) incorrectly suggest that medicines exhibit enhanced therapeutic actions, (b) influence the prescription patterns of physicians, or the acquisition of OTC medicines by patients. ${ }^{2}$ Although the expressions 'Rapid', 'Pediatric', 'Infant', and 'Adult' are also not recommended, their use might be explained by the following facts: (a) in the case of insulin, 'Rapid' might facilitate the distinction from insulin with prolonged action and similar names, and (b) 'Pediatric', 'Infant' and 'Adult' might facilitate the identification of the population group for which the medicinal product is intended ${ }^{2}$.

\section{Limitations}

The formal similarity of medicine brand names, such as Dynapen ${ }^{\circledR}$ and Dynacirc ${ }^{\circledR 12}$, was not specifically evaluated, because as far we know there are no specific automatic tools that allow performing this task in Portuguese. This screening is very important, due to the risk of potential confusions between similar drug names, with potential harm to the patient ${ }^{10-13}$. The same type of screening using the names of generic products, medical devices, or other body-care products would also be advisable.

\section{Practical Implications}

Regulation should state/define the most adequate linguistic characteristics for each language to assure the readability of medicines names by the local relevant users.

The linguistic characteristics of brand names are very important to the commercialization and marketing of medicines, because these features might influence the adequate memorization and pronunciation of brand names by health professionals and patients. Also, the use of similar names might be misunderstood by patients ${ }^{12,14}$. Besides performing descriptive and qualitative studies, it is also advisable the realization of experimental studies with patients for defining the best word shapes for the adequate memorization, recall and design of brand names for each language. Furthermore, to date there are no specific golden rules for developing the name of brand medicines in Portuguese. The suitability of medicine brand names for a certain speaking/reading population should be investigated for each individual language, because linguistic rules and orthographic conventions vary cross-linguistically $^{48}$. Similar experimental studies are also recommended to the names of generic medicines.

Software tools specifically developed to study the characteristics of Portuguese brand names, such as the automatic detection of phonological neighbors (different names that are almost identical in terms of their sound form), should be developed in order to avoid the approval of too similar names. The adaption of the brand names written in accordance with the orthographic system of other languages to Portuguese (e.g. the use of the letters $k, y$ and $w$ or non-canonical segments) seems also advisable, for instance following a procedure similar to that applied to the names of generic medicines (e.g. use of $i, t, f$ and $e$ instead of $y, t h, p h$ and ae respectively, for instance in 1) Pentoxifilina in Portuguese, that in English is translated as 'Pentoxifylline', 2) Petidina in Portuguese that in English is translated 'Pethidine', 3) Morfina in Portuguese that in English is translated as 'Morphine' and 4) Hemocoagulase in Portuguese that in English is translated as 'Haemocoagulase') 29,30.

Although the names of brand medicines were specifically investigated in this study, it is likely that the same or similar linguistic principles 
might be applicable to other Portuguese brands, such the brands of cosmetics, medical devices, food, generic medicines or herbal products ${ }^{49,50}$.

Given that Portuguese is the fifth most widely spoken language in the world (spoken by approximately 273 million people) $)^{51}$, the occurrence of the letters $k, y$ and $w$, that might be used within non-Portuguese words or non-canonical segments in the names of brand medicines might be especially important, because these names might also be marketed in many countries other than Portugal, where Portuguese is also the official language (e.g. Brazil, Angola, or Timor).

Moreover, the real impact of using certain orthographic patterns in the name of medicines is not completely clear/known (e.g. abbreviations/ symbols), consequently more research on the topic is needed. Regulatory authorities should be more involved in the supervision of medicine brand clarity and pronounceability during the process of medicines approval ${ }^{2}$. Besides of being involved in the creative process of inventing brand names, marketing authorization holders should assure their appropriateness.

\section{Conclusions}

Many issues were detected for the brand names in this study, which might promote a lower readability of Portuguese brand names. Overall, some names were formed by more than one word or contained letters only recently introduced in the Portuguese alphabet ( $\mathrm{y}, \mathrm{k}$ and $\mathrm{w})$, as well as non-canonical segments (or associations of letters non-existent in Portuguese), rare syllabic types, V-slots (rare segments/parts of words that are deviant from the common patterns of the language), abbreviations, numbers, symbols, hyphenated words, and prohibited expressions according to the pharmaceutical legislation. These suggest that some Portuguese brand names might need to be reevaluated by marketing authorization holders or medicines authorities. Updating the pharmaceutical regulation on this issue is also advisable, given that the linguistic features of brand names are not detailed enough in the Portuguese and European regulation.

\section{Collaborations}

C Pires, M Vigário and A Cavaco contributed to the conception, design, development, analysis and writing-up of the manuscript.

\section{Acknowledgments}

Fundação para a Ciência e a Tecnologia, Portugal. 


\section{Referências}

1. Handler SM, Nace DA, Studenski SA, Fridsma DB. Medication error reporting in long-term care. $A m J$ Geriatr Pharmacother 2004; 2(3):190-196.

2. Infarmed. Deliberação n. ${ }^{\circ} 144 / C D / 2012$ - Norma orientadora para a aceitação de nomes de medicamentos. [Resolution no. 144/CD/2012 - Guiding norm for the acceptance of the medicines names]; 2012. [accessed 2014 July 11]. Available at: http://www.infarmed.pt/portal/ page/portal/INFARMED/MEDICAMENTOS_USO_ HUMANO/AUTORIZACAO_DE_INTRODUCAO_ NO_MERCADO/144_DAM_91.pdf

3. Hyönä J, Bertram R, Pollatsek A. Are long compound words identified serially via their constituents? Evidence from an eye-movement-contingent display change study. Mem Cognit 2004; 32(4):523-532.

4. Institute for safe medication practice. ISMP'S List of confused drug names; 2011. [accessed 2014 July 14]. Available at: https://www.ismp.org/tools/confuseddrug names.pdf

5. Gonçalves C, Almeida ML. Morfologia Construcional: principais ideias, aplicação ao português e extensões necessárias. Alfa, rev. Linguíst 2014; 58(1):165-193.

6. Ulrich B. Preventing errors by eliminating mistake-prone abbreviations. Nephrol Nurs J 2007; 34(5): 473-502.

7. European Medicines Agency. Guideline on the acceptability of names for human medicinal products processed through the center procedure; 2007. [accessed 2014 July 17]. Available at: http://www.ema.europa.eu/docs/en _GB/document_library/Regulatory_and_procedural _guideline/2009/10/WC500004142.pdf

8. Therapeutics Goods Administration. Best practice guideline on prescription medicine labelling; 2011. [accessed 2014 July 11]. Available at: http://www.tga.gov. au/industry/labelling-pm-best-practice.htm\#.UxWvxvnV8qc

9. Food and Drug Administration. Guidance for industry contents of a complete submission for the evaluation of proprietary names; 2010. [accessed 2014 June 03]. Available at: http://www.fda.gov/downloads/Drugs/ GuidanceComplianceRegulatoryInformation/Guidances/ucm075068.pdf

10. Justi FR, Pinheiro AMV. O efeito de vizinhança ortográfica no português do Brasil: acesso lexical ou processamento estratégico. Rev Interam Psicol 2006; 40(3):275-288.

11. Aronson JK. Medication errors resulting from the confusion of drug names. Expert Opin Drug Saf 2004; 3(3):167-172.

12. Lambert BL, Lin SJ, Tan H. Designing safe drug names. Drug Saf 2005; 28(6):495-512.

13. Lambert BL, Lin SJ, Chang KY, Gandhi SK. Similarity to the risk factor in drug-name Confusion errors: the look-alikes (orthographic) and sound-alikes ("phonetic”), model. Med Care 1999; 37(12):1214-1225.
14. Lambert BL, Chang KY, Lin SJ. Descriptive analysis of the drug name lexicon. Drug Information Journal 2001; 35(1):163-172.

15. New B, Ferrand L, Pallier C, Brysbaert M. Reexamining the word length effect in visual word recognition: New evidence from the English Lexicon Project. Psychon Bull Rev 2006; 13(1):45-52.

16. Balota DA, Yap MJ, Cortese MJ, Hutchison KA, kessler B, Loftis B, Neely JH, Nelson DL, Simpson GB, Treiman R. The English Lexicon Project. Behav Res Methods 2007; 39(3):445-459.

17. Castelo A, Freitas MJ, Miguens F. Níveis de escolaridade e a capacidade de segmentação de palavras. 2010. [accessed 2014 July 11]. Available at: http://www.clul. ul.pt/files/anagrama/Castelo_Freitas_Miguens_2010. pdf

18. Aguiar J, Vigário M. Contributo para o estudo da variação na frequência de unidades e padrões fonológicos. In: XXV National meeting of the Portuguese Association of Linguistics, 2010.

19. Mateus MH, Andrade E. The Phonology of the Portuguese. Oxford: Oxford University Press; 2000.

20. Frota S, Vigário M, Martins F, Cruz M. FrePOP: Frequency patterns of phonological objects in Portuguese (version 1.0) [Database].

21. Pereira TA, Montero EF. Terminologia DeCS e as novas regras ortográficas da língua portuguesa: orientações para uma atualização. Acta Cir. Bras 2012; 27(7):509514.

22. Cooper N, Cutler A, Wales R. Constraints of lexical stress on lexical access in English: evidence from native and non-native listeners. Lang Speech 2002; 45(Pt 3):207-228.

23. Soto-Faracoa S, Sebastián-Gallésa N, Cutler A. Segmental and suprasegmental mismatch in lexical access. J Mem Lang 2001; 45:412-432.

24. Ferrand L, New B. Syllabic length effects in visual word recognition and naming. Acta Psychol (Amst) 2003; 113(2):167-183.

25. Mezzomo CL, Dias RF, Vargas DZ. Fatores intervenientes na produção correta da sílaba (c)vc em dados típicos e atípicos de fala. Delta 2014; 30(2):353-370.

26. Vigário M, Martins F, Frota S. A ferramenta FreP e a frequência de tipos silábicos e de classes de segmentos no Português. In: XXI National meeting of the Portuguese Association of Linguistics, 2006.

27. Vigário M, Freitas MJ, Frota S. Grammar and frequency effects in the acquisition of prosodic words in European Portuguese. Lang Speech 2006; 49(2):175-203.

28. Infarmed. Prontuário Nacional Terapêutico. [National Prescribing Guide]; 2011. [accessed 2014 June 03]. Available at: http://www.infarmed.pt/portal/pls/portal /!PORTAL.wwpob_page.show?_docname=7118264. PDF 
29. American Medical Association. Rules for coining names; 2014. [accessed 2014 July 17]. Available at: http://www. ama-assn.org/ama/pub/physician-resources/medical-science/united-states-adopted-names-council/ naming-guidelines.page?

30. Infarmed. Vademecum. [Handbook]; 2005. [accessed 2014 June 03]. Available at: http://www.infarmed.pt/ portal/page/portal/INFARMED/PUBLICACOES/ TEMATICOS/VADEMECUM/vademecum.pdf

31. World Health Organization. Guidelines on the Use of International Nonproprietary Names for Pharmaceutical Substances; 1997. [accessed 2014 July 11]. Available at: http://apps.who.int/medicinedocs/en/d/Jh1806e/

32. Mateus MH, Brito AM, Duarte I, Faria IH, Frota S, Matos G, Oliveira F, Vigário M, Villalva. Gramática da Lingua Portuguesa. Lisboa, Portugal: Caminho; 2004.

33. Martins F, Vigário M, Frota S. FreP: Frequency Patterns of phonological objects in Portuguese (version 2.0) [Software].

34. Eurostat. Level of the foreign language reported as best-known in the country (self-reported) by sex. [accessed 2014 June 15]. Available at: http://appsso.eurostat.ec.europa.eu/nui/show.do?dataset=edat_aes_ 151\&lang=en

35. Trancoso I, Ribeiro MC. On the pronunciation mode of acronyms in several european languages. In: George K, Nikos F, Evangelos D, Fifth European Conference on Speech Technology; 1997. [accessed 2014 July 11]. Available at: http://www.informatik.uni-trier.de/ ley/ $\mathrm{db} /$ conf/interspeech/eurospeech1997.html

36. European Parliament. Directive 2004 /27/EC amending Directive 2001/83/EC on the Community code relating to medicinal products for human use; 2004. [accessed 2014 June 15]. Available at: http://ec.europa.eu/health/files/ eudralex/vol-1/dir_2004_27/dir_2004_27_en.pdf

37. Nobre PF. Off-label prescriptions in Brazil and in the US: legal aspects and paradoxes. Cien Saude Colet 2014; 18(3):847-854.

38. European Medicines Agency. Guideline on the readability of the labelling and package leaflet; 2009. [accessed 2014 June 15]. Available at: http://ec.europa.eu/health/ files/eudralex/vol-2/c/2009_01_12_readability_guideline_final_en.pdf

39. Medilexicon. Medical Abbreviations Dictionary; 2014. [accessed 2014 July 11]. Available at: http://www.medilexicon.com/medicalabbreviations.php

40. Infarmed. Infomed: public data base containing informations about the Portuguese medicines; 2014. [accessed 2014 July 11]. Available at: http://www.infarmed.pt/ infomed/inicio.php

41. Nespor M, Vogel I. Prosodic Phonology. Dordrecht: Mouton de Gruyter; 1986.
42. Viana FL, Ribeiro IS, Maia J, Santos S. Propriedades psicométricas da prova de reconhecimento de palavras. Psicol. Reflex. Crit. 2013; 26(2):231-240.

43. Kenagy JW, Stein GC. Naming, labelling, and packaging of pharmaceuticals. Am J Health Syst Pharm 2001; 58(21):2033-2041.

44. Yap MJ, Balota DA, Sibley DE, Ratcliff R. Individual differences in visual word recognition: insights from the English Lexicon Project. J Exp Psychol Hum Percept Perform 2012; 38(1):53-79.

45. Marian V, Bartolotti J, Chabal S, Shook A. CLEARPOND: cross-linguistic easy-access resource for phonological and orthographic neighborhood densities. PLoS One 2012; 7(8):e43230.

46. Food and Drug Administration. Consumers filling U.S. prescriptions abroad may get the wrong active ingredient because of confusing drug names; 2006. [accessed 2014 June 03]. Available at: http://www.fda.gov/Drugs/ DrugSafety/PostmarketDrugSafetyInformationforPatientsandProviders/ucm173134.htm

47. Cavaco A, Pires C, Vigário M. Medicine package inserts abbreviations and acronyms in Portuguese: exploring how difficult they are for educated people, in Medical Encounter. American Academy on Communication in Healthcare 2014; 27(2).

48. Rohrmeier M, Fu Q, Dienes Z. Implicit learning of recursive context-free grammars. PLoS One 2012; 7(10): e45885.

49. Bruning MC, Mosegui GB, Vianna CM. The use of phytotherapy and medicinal plants in primary healthcare units in the cities of Cascavel and Foz do Iguaçu - Paraná: the viewpoint of health professionals. Cien Saude Colet 2012; 17(10):2675-2685.

50. Blatt CR, Trauthman SC, Schmidt EH, Marchesan S, da Silva LM, Martins JL. General awareness and use of generic medication among citizens of Tubarão, state of Santa Catarina, Brazil. Cien Saude Colet 2012; 17(1):7987.

51. World's Observatory. The 100 most spoken languages on the world; 2009. [accessed 2014 Jul 11]. Available at: http://frankherles.wordpress.com/2009/06/28/the100-most-spoken-languages-on-the-world/

Artigo apresentado em 14/09/2014

Aprovado em 27/11/2014

Versão final apresentada 29/11/2014 